\title{
NK Cell-enriched Donor Lymphocytes
}

National Cancer Institute

\section{Source}

National Cancer Institute. NK Cell-enriched Donor Lymphocytes. NCI Thesaurus. Code C127939.

A preparation of donor-derived lymphocytes that are enriched for donor-derived natural killer (NK) cells, with direct tumor cytotoxic activity. Following allogeneic stem cell transplantation and subsequent infusion of the NK cell-enriched donor lymphocytes, these cells recognize and bind to tumor cells, upon which they secrete and release perforins, granzymes, and cytokines, which results in cancer cell lysis. Infusion of donor lymphocytes is limited by the risk of graft-versus-host disease (GVHD) and NK cells normally constitute only a small portion of circulating lymphocytes. Therefore, NK cellenrichment may result in higher amounts of NK cells per infusion and improved antitumor immunity without increasing the risk of GVHD. 